\title{
The Psychometric Properties of an Arabic Version of Multiple Intelligence Development Assessment Scale for Adolescents (TEEN-MIDAS)
}

\author{
Sabah Hasan Al-Onizat \\ Learning Disability and Gifted Education, Faculty of Education, The World Islamic Sciences \& Education \\ University (W.I.S.E), Jordan, Amman \\ Email: dr sabah@hotmail.com
}

Received 1 March 2014; revised 1 April 2014; accepted 8 April 2014

Copyright (C) 2014 by author and Scientific Research Publishing Inc.

This work is licensed under the Creative Commons Attribution International License (CC BY). http://creativecommons.org/licenses/by/4.0/

(c) (i) Open Access

\section{Abstract}

This study deals with the psychometric properties and derivation of norms for an Arabic version of the Multiple Intelligence Development Assessment Scale for Adolescents (TEEN-MIDAS). The standardization sample consisted of 637 students (317 males, 320 females) ranging from 14 - 16 years in age. Factor analysis and one-way ANOVA reveal a good construct, factorial, and discriminatory validity. The Cronbach- $a$ formula was used to estimate internal consistency coefficients. Split half and test-retest procedures were also used to establish reliability coefficients. All the results indicate acceptable reliability for the TEEN-MIDAS. The intelligence scores were distributed normally in terms of the age range. And the deviation for the intelligences degrees and percentiles were calculated for each group of the sample. Finally, results indicated no statistical difference at $(\alpha=0.05)$ among males and females students in the total scale, even though the musical and spatial intelligences were found higher among females than males and natural intelligence higher among males than females. Overall, the TEEN-MIDAS appears to have acceptable psychometric characteristics allowing for its use in decision making about career classification and selection.

\section{Keywords}

Psychometric Properties, Multiple Intelligence, (TEEN-MIDAS) Scale

\section{Background}

Throughout the history of psychology, the concept of intelligence and methods of measurement have been major

How to cite this paper: Al-Onizat, S. H. (2014). The Psychometric Properties of an Arabic Version of Multiple Intelligence Development Assessment Scale for Adolescents (TEEN-MIDAS). Creative Education, 5, 590-605. 
concerns for both psychologists and educators, as they try either to understand how children learn or assist in predicting future performance (Deary, 2000, 2001; Vernon, 1979).

After Alfred Binet developed the first test of cognitive abilities in 1905, various theories emerged that agree on the basic conceptual definition of intelligence, i.e., the overall capacity for learning and problem solving as exemplified by the intelligence quotient (IQ) as measured by intelligence tests (e.g., Binet and Weschler tests. See: Mackintosh, 1998; Sternberg, 1990).

There is, however, an extensive and growing literature on intelligence theory that indicates that existing differences often depend on whether intelligence is a unitary or multifaceted capacity (Paulhus, 2000; Sternberg, 1990).

In the unitary approach to intelligence the most popular theory is that posit by Thorndike (1927). He believed mental capacities divide into three clusters, i.e., social, concrete, and abstract intelligence (Murphy, 1949; Parmalee, 1985; Thurston, 1983). Spearman (1927) speculated everyone has general intelligence factor (g), and specific task related ability (s) (Byrd \& Stacey, 1993; Eysenck, 1998).

Multi-factored models of intelligence have also been introduced over the years. For example, Thurston introduced his Primary Mental Abilities theory in 1938, and in 1967 Guilford offered his complex structure intellect model. This involved 150 factors derived from three categories, i.e., operation, content, and product. Thus, intelligence could be understood through mental operation that carried out on specific contents so as to get the result (Horn, 1989; Parmelee, 1985). More recently, Goleman (1995) offered his emotional intelligence (EI) theory. For a variety of reasons, these alternative theories of intelligence have failed to enjoy wide acceptance or application in education or psychology (Gould, 1981).

Howard Gardner (1983, 1993, 1999) has challenged all the unitary general intelligence, supporting, rather, a theory of multiple intelligence (MI). He believes a unitary theory fails to reflect the real strength and ability possessed by an individual. He proposed each individual has multiple abilities or multiple intelligence. Initially seven primary intelligences were identified (later he added eighth \& ninth intelligence) as being possessed in varying degrees and which when combined in various ways created a unique cognitive structure.

Gardner (1994) defined human intelligence as the "bio-social potential that allows a person to solve problems and create products that are valued within a community” (p. 577). Employing this definition Gardner covers a broad range of capabilities, which should meet a range of criteria to qualify as an intelligence in Gardner's MI theory, and these criteria are: the potential for isolated breakdown of the skill through brain damage, support from psychology training studies and from psychometric studies, including correlation across tests; evolutionary plausibility; and distinct developmental history culminating in a definable set of operation or set of end state performances. In addition, each intelligence has to have an identifiable set of operations, as well as susceptibility to coding in symbol system (Feldman, 1998). The eight intelligences identified by MI theory are: linguistic, logical-mathematical, spatial, musical, bodily-kinesthetic, interpersonal, and intrapersonal, Naturalist, and in 1999 he added the ninth intelligence; existential intelligence, but it not largely meet the eight criteria in order to be included on the list of intelligences.

The following descriptions summarize key features of the multiple intelligences:

1) Verbal/linguistic intelligence: ability to think in words and to use language to express , understand complex meanings, Sensitivity to the meaning of words and the order among words, sounds, rhythms, inflections. And the ability to reflect on the use of language in everyday life, and these linguistic skills is important for providing explanations, descriptions and expressiveness.

2) Logical/mathematical intelligence: ability to think of cause and effect connections to understand relationships among actions, objects or ideas. And the ability to use numbers and logic effectively, skill in calculation, logical reasoning, and problem solving.

3) Musical intelligence: sensitivity to understanding of the pitch, rhythm, timbre, and the tone. To recognize, create and reproduce music by using an instrument or voice. Active listening and a strong connection between music and emotions.

4) Bodily kinesthetic intelligence: ability to think in movements and use one's body in differentiated ways for expressive the thought and feeling for goal directed activities.

5) Spatial intelligence: ability to think in pictures and to perceive the visual world, the ability to think in threedimensions, to transform one's perceptions and re-create aspects of one's visual experience via imagination to work with objects effectively.

6) Naturalistic intelligence: ability to understand recognition and display empathy for living and natural things, 
and to recognize and classify individuals, species and ecological relationships. To interact effectively with living creatures and discern patterns of life and natural forces.

7) Intrapersonal intelligence: ability to look inside the self and assess one's own personal strengths, weaknesses, and motivations, and accurate self-appraisal, self-monitoring, goal setting, and emotion management. The ability to monitor one's self in interpersonal relationships and to act with personal efficacy.

8) Interpersonal intelligence: ability to recognize the emotions, mood, perspectives and motivation in other people, to notice and distinctions among other people. It involves interacting effectively with one or more people in familiar, casual or working circumstances (Gardner, 1983, 1993; Armstrong, 1994, 1999).

In the field of measurement and psychology, psychometric properties of tests based on the theory validity and reliability were established usually to validate a theory of intelligence. Validity refers to the degree to which a test measures its intended attributes or desired outcomes. Although there are lots of kinds of validity, the most often reported in the manual of standardized intelligence tests is concurrent validity. It is usually established by comparing scores on test with scores of other standardized tests of the same standard (Esters \& Ittenbach, 1999). In addition, reliability refers to the consistency of a tests result over time and is usually determined by using or more of the following methods test-retest, equivalent-form, and split-half. Correlation is the statistical process that all standardized intelligence test use to document the degree of validity and reliability. Validity and reliability are useful measures for testing the theoretical construct that human intelligence is a general ability that remains stable over time (Chen, 2004). Moreover, the validation of the original English version of Multiple Intelligence Development Assessment Scales (MIDAS) has been examined by a series of investigations, which assess its construct, concurrent, and predictive validity. Whereas there is a subset of MIDAS gizmo that inquire the active participation and expressed enthusiasm for lots of the MI activities. The MIDAS instrument was designed to provide an objective measure of the multiple intelligence as reported by the person or by a knowledgeable informant.

\section{General Description of the MIDAS}

Although Gardner's MI Theory has been highly praised in the educational field because of its potential applications (Eisner, 1994; Shearer \& Jones, 1994), it has not received widespread attention within the scientific community. There has been a noticeable lack of supporting research and substantiating reliability and validity tests (Collins, 1998; Shearer \& Jones, 1994; Sternberg, 1994; Traub, 1998). In fact, by 1994, 11 years after the presentation of the theory, there were no published empirical tests validating the theory scientifically—not even by Gardner himself (Sternberg, 1994). By 1997, though, a series of studies emerged to measure objectively and validate the intelligences posited by Gardner's theory (Shearer, 1991, 1996a, 1997; Shearer \& Jones, 1994; Way \& Shearer, 1990). Defining an intelligence as "the ability to solve a problem or create a product that is valued within one or more cultures” (Shearer, 1997: p. 2), these studies demonstrated that each of Gardner's proposed intelligences was indeed a distinct, identifiable construct that had an anatomical representation in the brain and could be effectively measured by one or more existing intellectual scales. These studies also led to the development of the Multiple Intelligences Developmental Assessment Scales (MIDAS), which was designed to measure the eight intellectual constructs described by Gardner's MI theory as well as three intellectual styles-Leadership, General Logic, and Innovation (Gardner, 1983).

The Multiple Intelligence Development Assessment Scales (MIDAS) were developed in 1987 to assess Gardener's eight intelligences via an objective, psychometrically-sound instrument, provide qualitative information and quantitative data about the human mental capabilities. It may be administered to adolescents, adults and children (Shearer, 1996). There is a 106-item MIDAS for individuals above 18 years; a test modified for teens, i.e., individuals between the ages for 14 and 18; a MIDAS-KIDS for children ages 9 - 14 and finally a version for 6 to 9 year old children. Administration of MIDAS is by way of self-report or structured interview. Participants respond to all MIDAS items according to a six-point Likert-type scale, i.e., "Always" (5) through to "Never" or "Very little" (0). An "I don't know" or "Does not apply" option is provided for every question in order to help the respondent avoid simply guessing or answer beyond his/her actual level of knowledge. The MIDAS items are written in one of three basic forms, i.e., those that:

- Assess the frequency or duration of time the child spends engaged in an activity.

- Ask for give a realistic evaluation of child's performance on an activity.

- Provide an assessment of the child's enthusiasm for an activity. 
The MIDAS has two major characteristics: 1) results are easily understood because the items possess an everyday common-sense meaning, and 2) results may be easily translated in terms of predicting potential success in various education and vocational settings.

The MIDAS is applied in various settings, including education, counseling, rehabilitation and other situations where a broad and descriptive assessment of individual's intellectual ability would be beneficial.

\section{Psychometric Properties}

Numerous cross-cultural studies have been conducted to investigate the reliability and validity of the MIDAS. These are summarized in detail in the Professional Manual. These studies generally identify MIDAS as having favorable psychometric properties with regards to factor structure, internal consistency (Cronbach- $a$ coefficients ranging 0.85 to 0.90 ), test-retest reliability, and concurrent validity (Shearer \& Jones, 1994). The MIDAS measures eight constructs and consists of 119 items (Wiswell, Hardy, \& Reio, 2001; Yoong, 2000).

\section{Statement of the Problem}

A valid and reliable tool such as MIDAS would provide Jordanian decision makers, teachers and parents a clearer, more comprehensive, insight into Jordanian student multiple intelligence. There is a need however, to derive the norms for a Jordanian version of Multiple Intelligence Development Assessment Scales (TEENMIDAS), while investigating the validity and reliability of such an instrument.

\subsection{Methods}

This study adapts and validates an Arabic version of MIDAS. This part of study discusses the research methodology and techniques used, the rational for the methodology used and describes the considerations influencing the development of research techniques and procedures.

\subsection{Subjects}

A sample of secondary-aged students $(\mathrm{N}=637)$ from three regions in Jordan: sample of Amman city consisted 206 (104 female and 102 male), from Salt city consisted 224 (104 female and 120 male), from Zarqa City consisted 207 (112 female and 95 male).

Although secondary schools in Jordan differ in facilities offered, size and location they share similar in characteristics. A number of the schools are known as comprehensive schools. A comprehensive school has a large number of students from different places around the district and has more facilities compared with other schools in the region. The random sample for this study was chosen from these schools. A random stratified sample technique was used in order to represent more accurately the characteristics of the whole population in an age range of between 14 - 16 years.

\subsection{Procedures}

The TEEN-MIDAS was administered to participants in their classroom environments. The researcher explained the purpose and importance of their participation in this study. In addition, the participants were assured of the confidentiality of their responses which would only be used for research purposes. Blank answer sheets were distributed and participants were asked to fill in the information needed. Later question booklets were distributed and participants were instructed how to answer them. Approximately 35 minutes were taken to complete the test. Responses were entered into the computer for statistical analysis using SPSS (Version 19 package). After data analysis results were discussed. Based on findings, suggestions were made for further research and for instructional processes.

\section{Reliability}

The reliability of the MIDAS has been examined in terms of internal consistency (Cronbach- $a$ ), split half-procedure and test-retest reliability and the duration between the test and the retest is 15 days. The results are shown below Table 1.

The reliability coefficients ranged from 0.79 for spatial intelligence to 0.86 for intrapersonal intelligence. The 
Table 1. The reliability by internal consistency (Cronbach-a), split half-procedure and test-retest reliability.

\begin{tabular}{cccc}
\hline Type of intelligence & Internal consistency & Split half-procedure & Test-retest reliability \\
\hline Musical intelligence & 0.82 & 0.79 & 0.83 \\
Kinesthetic intelligence & 0.80 & 0.73 & 0.82 \\
Logical intelligence & 0.85 & 0.79 & 0.82 \\
Spatial intelligence & 0.79 & 0.79 & 0.80 \\
Linguistic intelligence & 0.80 & 0.77 & 0.81 \\
Interpersonal intelligence & 0.82 & 0.80 & 0.84 \\
Intrapersonal intelligence & 0.86 & 0.82 & 0.85 \\
Natural intelligence & 0.84 & 0.74 & 0.91 \\
Total multiple intelligences & 0.97 & 0.88 & 0.90 \\
\hline
\end{tabular}

whole scale was 0.97 . The reliability by the split half-procedure was between 0.73 of kinesthetic intelligence to 0.82 for intrapersonal intelligence. The whole scale was 0.88 . Test-retest reliability coefficients ranged from 0.91 for naturalistic intelligence to 0.85 for intrapersonal intelligence. The scale as a whole was 0.90 . All results suggest that levels of variance are acceptable.

\section{Affirmation of Validity}

\subsection{Content Validity}

Gardner himself provided the content validity of the original English language version of MIDAS (Shearer, 1996). The first step taken to establish the validity of an Arabic version of MIDAS was a translation and backtranslation of the English language version into Arabic. This was followed by content validity using expert judgment and a pilot study using items into Arabic. Stringent instrument development was involved in item construction, scale composition, sub-scales creation and expert judgment to improve content validity. The translated Arabic version of MIDAS was reviewed by ten experts at Jordan University and Arabian Amman University. Their comments and suggestions were used to modify and refine the items in the Arabic version. This review resulted in 26 of the 119 items being deleted. Eight of the ten experts agreed the deleted items were not culturally appropriate to Jordan. The total number of items was reduced to 93. In addition, fifteen items were modified. A pilot study was launched involving a mixed gender group of (75) students from two schools in Jordan. The purpose of study was to determine the overall reliability for the Arabic version of MIDAS and the reliabilities of its subscales. The reliability coefficient computed was obtained using test-retest method.

\subsection{Factorial Validity}

Correlation coefficients were determined for each item with the total degree of each intelligence. Table 2 shows results greater than 0.39 . The results appear supportive of the scale construction. Where the Correlation coefficients ranged between $(0.39$ - 0.64) for the music intelligence, and between $(0.41-0.57)$ for the Kinesthetic intelligence, and between $(0.45-0.60)$ for the logical intelligence, and between $(0.45-0.61)$ for the spatial intelligence, and between $(0.39-0.54)$ for the Linguistic intelligence, and between $(0.41-0.54)$ for the interpersonal intelligence, and between $(0.37-0.58)$ for the intrapersonal intelligence, and ranged between $(0.38-0.57)$ for the natural intelligence.

Also, The correlation coefficients between scores of individuals on multiple intelligences was extracted, and the result shown in the Table 3 that the correlation coefficients are statistically significant at a level of 0.05 among all grades of the different intelligences. These coefficients have ranged between 0.30 between for the musical intelligence and intrapersonal intelligence, and to 0.65 for the relationship between interpersonal intelligence and intrapersonal intelligence, and the existence of these significant correlations confirm the construction of the scale. 
Table 2. Correlation coefficients of MI items with the total degree of the overall intelligence.

\begin{tabular}{|c|c|c|c|c|c|}
\hline \multicolumn{2}{|c|}{ Musical intelligence } & \multicolumn{2}{|c|}{ Kinesthetic intelligence } & \multicolumn{2}{|c|}{ Logical intelligence } \\
\hline $\begin{array}{l}\text { Item num in } \\
\text { MIDAS scale }\end{array}$ & $\begin{array}{c}\text { Correlation } \\
\text { coefficient }\end{array}$ & $\begin{array}{l}\text { Item num in } \\
\text { MIDAS scale }\end{array}$ & $\begin{array}{l}\text { Correlation } \\
\text { coefficient }\end{array}$ & $\begin{array}{l}\text { Item num in } \\
\text { MIDAS scale }\end{array}$ & $\begin{array}{l}\text { Correlation } \\
\text { coefficient }\end{array}$ \\
\hline 1 & 0.39 & 12 & 0.48 & 22 & 0.50 \\
\hline 2 & 0.49 & 13 & 0.57 & 23 & 0.52 \\
\hline 3 & 0.56 & 14 & 0.54 & 24 & 0.51 \\
\hline 4 & 0.61 & 15 & 0.41 & 25 & 0.55 \\
\hline 5 & 0.47 & 16 & 0.42 & 26 & 0.56 \\
\hline 6 & 0.51 & 17 & 0.44 & 27 & 0.50 \\
\hline 7 & 0.50 & 18 & 0.44 & 28 & 0.45 \\
\hline 8 & 0.57 & 19 & 0.54 & 29 & 0.46 \\
\hline 9 & 0.64 & 20 & 0.52 & 30 & 0.60 \\
\hline 10 & 0.58 & 21 & 0.50 & & \\
\hline 11 & 00.42 & & & & \\
\hline \multicolumn{2}{|c|}{ Spatial intelligence } & \multicolumn{2}{|c|}{ Linguistic intelligence } & \multicolumn{2}{|c|}{ Interpersonal intelligence } \\
\hline $\begin{array}{l}\text { Item num in } \\
\text { MIDAS scale }\end{array}$ & $\begin{array}{l}\text { Correlation } \\
\text { coefficient }\end{array}$ & $\begin{array}{l}\text { Item num in } \\
\text { MIDAS scale }\end{array}$ & $\begin{array}{l}\text { Correlation } \\
\text { coefficient }\end{array}$ & $\begin{array}{l}\text { Item num in } \\
\text { MIDAS scale }\end{array}$ & $\begin{array}{l}\text { Correlation } \\
\text { coefficient }\end{array}$ \\
\hline 31 & 0.47 & 41 & 0.40 & 54 & 0.43 \\
\hline 32 & 0.57 & 42 & 0.45 & 55 & 0.47 \\
\hline 33 & 0.61 & 43 & 0.44 & 5 & 0.54 \\
\hline 34 & 0.45 & 44 & 0.44 & 57 & 0.49 \\
\hline 35 & 0.53 & 45 & 0.46 & 58 & 0.43 \\
\hline 36 & 0.46 & 46 & 0.45 & 59 & 0.44 \\
\hline 37 & 0.49 & 47 & 0.47 & 60 & 0.45 \\
\hline 38 & 0.48 & 48 & 0.39 & 61 & 0.42 \\
\hline 39 & 0.53 & 49 & 0.41 & 62 & 0.52 \\
\hline \multirow[t]{5}{*}{40} & 0.50 & 50 & 0.40 & 63 & 0.53 \\
\hline & & 51 & 0.54 & 64 & 0.46 \\
\hline & & 52 & 0.40 & 65 & 0.41 \\
\hline & & 53 & 0.48 & 66 & 0.50 \\
\hline & & & 67 & 0.53 & \\
\hline \multicolumn{2}{|c|}{ Intrapersonal intelligence } & \multicolumn{2}{|c|}{ Natural intelligence } & & \\
\hline $\begin{array}{l}\text { Item num in } \\
\text { MIDAS scale }\end{array}$ & $\begin{array}{l}\text { Correlation } \\
\text { coefficient }\end{array}$ & $\begin{array}{l}\text { Item num in } \\
\text { MIDAS scale }\end{array}$ & $\begin{array}{l}\text { Correlation } \\
\text { coefficient }\end{array}$ & & \\
\hline 68 & 0.37 & 81 & 0.47 & & \\
\hline 69 & 0.47 & 82 & 0.57 & & \\
\hline 70 & 0.45 & 83 & 0.50 & & \\
\hline 71 & 0.46 & 84 & 0.38 & & \\
\hline 72 & 0.52 & 85 & 0.49 & & \\
\hline 73 & 0.51 & 86 & 0.56 & & \\
\hline 74 & 0.48 & 87 & 0.52 & & \\
\hline 75 & 0.58 & 88 & 0.54 & & \\
\hline 76 & 0.52 & 89 & 0.54 & & \\
\hline 77 & 0.54 & 90 & 0.51 & & \\
\hline 78 & 0.51 & 91 & 0.46 & & \\
\hline 79 & 0.45 & 92 & 0.53 & & \\
\hline 80 & 0.48 & 93 & 0.49 & & \\
\hline
\end{tabular}


Table 3. Correlation coefficients of multiple intelligences with each other.

\begin{tabular}{|c|c|c|c|c|c|c|c|c|c|}
\hline Type of intelligences & Mus & Kin & $\log$ & Spat & Ling & Inter & Intra & Nat & Total multiple \\
\hline Mus & 1 & $0.54^{*}$ & $0.32^{*}$ & $0.44^{*}$ & $0.40^{*}$ & $0.36^{*}$ & $0.30^{*}$ & $0.31^{*}$ & $0.61^{*}$ \\
\hline Kin & & 1 & $0.40^{*}$ & $0.56^{*}$ & $0.48^{*}$ & $0.45^{*}$ & $0.39^{*}$ & $0.42^{*}$ & $0.72^{*}$ \\
\hline $\log$ & & & 1 & $0.48^{*}$ & $0.55^{*}$ & $0.53^{*}$ & $0.50^{*}$ & $0.37^{*}$ & $0.68^{*}$ \\
\hline Spat & & & & 1 & $0.56^{*}$ & $0.52^{*}$ & $0.48^{*}$ & $0.47^{*}$ & $0.76^{*}$ \\
\hline Ling & & & & & 1 & $0.62^{*}$ & $0.60^{*}$ & $0.40^{*}$ & $0.79^{*}$ \\
\hline Interp & & & & & & 1 & $0.65^{*}$ & $0.45^{*}$ & $0.81^{*}$ \\
\hline Intrap & & & & & & & 1 & $0.42^{*}$ & $0.77^{*}$ \\
\hline Nat & & & & & & & & 1 & $0.66^{*}$ \\
\hline Total multiple & & & & & & & & & 1 \\
\hline
\end{tabular}

\subsection{Discrimination Validity}

First: Discrimination according to the type of students (gifted and non-gifted students):

To examine differences in the degree of multiple intelligences among gifted students and non-gifted students the t-test was applied to examine the capacity of the scale to distinguish between these two categories and the results are shown in the Table 4.

And the results show the following:

There is a statistically significant difference at the 0.05 level, at the overall average of the multiple intelligences, and the average of: musical intelligence, kinesthetic intelligence, logical intelligence, spatial intelligence, linguistic intelligence, interpersonal intelligence, natural intelligence, and the arithmetic averages of this differences in intelligences was in favor of gifted students.

But there is no statistically significant difference at the 0.05 level at the average intrapersonal intelligence, the value of $\mathrm{T}$ was (1.77). The arithmetic mean of gifted students (66.4), while the averages of non-gifted students is (64.39).

It appears from the previous results that MIDAS have the ability to show the difference between gifted and non-gifted students, and found that all were in favor of Gifted and thus improve that the MIDAS have discriminatory validity.

Second: discrimination according to the gender (male and female students):

The arithmetic mean and standard deviations for scores of individuals on multiple intelligences according to the Gender Table 5 shows the results.

The result of analysis shown the follows:

There is no statistically significant difference in the overall average of the multiple intelligences between male and female, the arithmetic average for males (61.6) and amounted to females (60.4). But there are differing in degrees of some intelligences, the female have a higher performance in musical intelligence with averages (55.4), while the males averages (49.4), and in spatial intelligence with averages (60.3), while the males averages (58.0) and in linguistic intelligence with averages (67.0), while the males averages (63.9), while the males have a higher performance only in natural intelligence with averages (62.9) while the females averages (58.0).

\section{Measures of Adapting the Original Scale to the Arabic Version}

After verifying the implications of reliability and validity that was displayed previously for the purpose of Adapting of multiple intelligences scale. The scale has been applied on a sample consisted of 637 students from ages (14 to 16), males and females, and to achieve this, the researcher, including the following:

1) Degrees were given to the answers of each question in the scale, as the following:

- One degree if the answer is (a).

- Tow degree If the answer is (b).

- Three degrees If the answer is (c). 
Table 4. The results of t-test to examine differences in the degree of multiple intelligences among gifted and non-gifted students.

\begin{tabular}{ccccccc}
\hline \multirow{2}{*}{ Type of intell } & \multicolumn{2}{c}{ Gifted } & \multicolumn{2}{c}{ Non-gifted } & Value T (degrees & Sig level \\
\cline { 2 - 6 } of freedom $=(635)$ & Arith mean & Standard dev & \\
\cline { 2 - 6 } Mus & Arith mean & Standard dev & 52.43 & 14.91 & 6.83 & 0.000 \\
Kin & 60.43 & 17.75 & 60.83 & 13.33 & 2.67 & 0.008 \\
Log & 63.55 & 14.49 & 61.48 & 13.04 & 5.39 & 0.000 \\
Spat & 66.87 & 14.45 & 59.15 & 14.46 & 2.99 & 0.000 \\
Ling & 62.48 & 16.21 & 65.44 & 11.72 & 2.06 & 0.039 \\
Inter & 67.34 & 13.79 & 60.81 & 13.26 & 4.43 & 0.000 \\
Intra & 65.26 & 14.08 & 64.39 & 15.12 & 1.77 & 0.077 \\
Nat & 66.40 & 15.47 & 60.43 & 14.37 & 3.31 & 0.001 \\
Total intell & 64.05 & 15.47 & 61.03 & 9.51 & 5.06 & 0.000 \\
\hline
\end{tabular}

Table 5. The mean and standard deviations of the MIDAS items according to the gender.

\begin{tabular}{|c|c|c|c|c|c|c|}
\hline \multirow{2}{*}{ Type intell } & \multicolumn{2}{|c|}{ Female } & \multicolumn{2}{|c|}{ Male } & \multirow{2}{*}{$\begin{array}{l}\text { Value } \mathrm{T} \text { (degrees } \\
\text { of freedom = 635) }\end{array}$} & \multirow{2}{*}{ Sig leve } \\
\hline & Arith mean & Standard dev & Arith mean & Standard dev & & \\
\hline Mus & 55.4 & 14.8 & 49.4 & 14.5 & 5.1 & 0.000 \\
\hline Kin & 61.6 & 13.4 & 60.1 & 13.2 & 1.4 & 0.153 \\
\hline $\log$ & 61.8 & 13.1 & 61.1 & 13.0 & 0.7 & 0.495 \\
\hline Spat & 60.3 & 14.7 & 58.0 & 14.1 & 2.1 & 0.037 \\
\hline Ling & 67.0 & 11.8 & 63.9 & 11.4 & 3.3 & 0.001 \\
\hline Inter & 60.8 & 13.5 & 60.8 & 13.0 & 0.1 & 0.957 \\
\hline Intra & 65.5 & 15.5 & 63.3 & 14.7 & 1.8 & 0.067 \\
\hline Nat & 58.0 & 14.2 & 62.9 & 14.1 & -4.4 & 0.000 \\
\hline Total intell & 61.6 & 9.6 & 60.4 & 9.4 & 1.6 & 0.100 \\
\hline
\end{tabular}

- Four degrees if the answer is (d).

- Zero degree if the answer is (f).

2) Sum the degrees of all the Subjects on items of every intelligence.

3) Divided the degrees obtained from the previous step on the number of items that represent every intelligence, then multiply the output with 20, to a maximum the IQ to 100 .

4) The distribution of data Verified by convert it to the nearest normal distribution (Normalizing) by extract the standard degree from the percentile and then transferred it to the same degrees in same average and standard deviation before the accommodation process of the data.

5) Extracted the percentile which corresponding to each expected degree of intelligences which obtained by the subjects—which appear in Table 6.

\subsection{Correcting the Scale and Extract the Raw Grades}

After applying, and to extract the degrees of multiple intelligences the followed steps are follows:

1) Degrees were given to the answers of each question in the scale, as the following:

- One degree if the answer is (a). 
Table 6. The percentiles corresponding to the degrees of multiple intelligences and the total degree.

\begin{tabular}{|c|c|c|c|c|c|c|c|c|c|}
\hline Percentiles & Mus & Kin & $\log$ & Spat & Ling & Inter & Intra & Nat & Total intell \\
\hline 1 & 19 and less & 26 and less & 30 and less & 29 and less & 35 and less & 30 and less & 28 and less & 29 and less & 40 and less \\
\hline 2 & 24 & $27-32$ & $31-37$ & $30-32$ & $36-41$ & $31-32$ & $29-33$ & $30-32$ & $41-42$ \\
\hline 3 & $25-27$ & $34-36$ & $38-40$ & $33-34$ & $42-44$ & $33-36$ & $34-36$ & 33 & 43 \\
\hline 4 & 28 & $37-38$ & & $35-36$ & 45 & 37 & $37-39$ & $34-35$ & $44-45$ \\
\hline 5 & 29 & 39 & 41 & 37 & $46-47$ & 38 & $40-41$ & $36-37$ & 46 \\
\hline 6 & 30 & 40 & & 38 & 48 & 39 & 42 & 38 & 47 \\
\hline 7 & 31 & 41 & 42 & 39 & 49 & 40 & 43 & 39 & 48 \\
\hline 8 & & 42 & & 40 & 50 & 41 & 44 & 40 & 49 \\
\hline 9 & 32 & 43 & 43 & 41 & 51 & 42 & 45 & 41 & 49 \\
\hline 10 & 33 & 44 & & 42 & & 43 & 46 & 42 & \\
\hline 11 & 34 & & 44 & & 52 & 44 & 47 & 43 & 50 \\
\hline 12 & & 45 & 45 & 43 & & 45 & 48 & 44 & \\
\hline 13 & 35 & & 46 & & 53 & 46 & 49 & & 51 \\
\hline 14 & 36 & 46 & 47 & 44 & & 47 & 50 & 45 & \\
\hline 15 & 37 & & 48 & & 54 & 48 & & & \\
\hline 16 & & 47 & & 45 & & & & 46 & 52 \\
\hline 17 & 38 & 48 & & & 55 & 49 & 51 & & \\
\hline 18 & 39 & & & 46 & & & & 47 & \\
\hline 19 & & 49 & 49 & & & & 52 & & 53 \\
\hline 20 & & & & 47 & 56 & 50 & & 48 & \\
\hline 21 & 40 & 50 & & & & & & & \\
\hline 22 & & & 51 & & & 51 & 53 & 49 & 54 \\
\hline 23 & 41 & 51 & 52 & & 57 & & & & \\
\hline 24 & 41 & & & 48 & & 52 & 54 & 50 & \\
\hline 25 & & 52 & 53 & & & 53 & & & 55 \\
\hline 26 & 42 & & & & 59 & & 55 & 51 & \\
\hline 27 & & 53 & 54 & & & 53 & & & \\
\hline 28 & & & & 49 & & & 56 & 52 & \\
\hline 29 & 43 & 54 & 55 & & & & & & \\
\hline 30 & & & & 50 & 60 & 54 & & 53 & 56 \\
\hline 31 & 44 & 54 & & & & & 57 & & \\
\hline 32 & & & & 51 & & & & 54 & \\
\hline
\end{tabular}




\section{Continued}

\begin{tabular}{|c|c|c|c|c|c|c|c|c|c|}
\hline 33 & 45 & & 56 & & & & & & \\
\hline 34 & & 55 & & 52 & & 55 & 58 & 54 & 57 \\
\hline 35 & 46 & & & & & & & & \\
\hline 36 & 47 & 56 & 57 & 53 & & & 59 & 55 & \\
\hline 37 & & & & & 61 & 56 & & & \\
\hline 38 & 48 & 57 & & 54 & & & & 56 & 58 \\
\hline 39 & & & 58 & & & & 60 & & \\
\hline 40 & & 58 & & & 62 & 57 & & 57 & \\
\hline \multicolumn{10}{|l|}{41} \\
\hline 42 & 49 & & 59 & 55 & & 58 & & & \\
\hline 43 & & 59 & & & 63 & & 61 & & 59 \\
\hline 44 & 50 & & & 56 & & & & 58 & \\
\hline 45 & & 60 & & & 64 & 59 & 62 & & \\
\hline 46 & & & 60 & 57 & & & & & \\
\hline 47 & 51 & & & & & & 63 & & \\
\hline 48 & & 61 & 61 & 58 & 65 & & & 59 & 60 \\
\hline 49 & & & & & & 60 & & & \\
\hline 50 & 52 & & 62 & 59 & & & 64 & 60 & \\
\hline 51 & & 62 & & & & & & & \\
\hline 52 & 53 & & 63 & 60 & & 61 & & & \\
\hline 53 & & 63 & & & 66 & & 65 & 61 & \\
\hline 54 & & & 64 & & & 62 & & 61 & \\
\hline 55 & 54 & & & 61 & & & 66 & & 61 \\
\hline 56 & & 64 & & & 67 & & & & \\
\hline 57 & & & 65 & 62 & & 63 & & 63 & \\
\hline 58 & 55 & 65 & & & 68 & & & & \\
\hline 59 & & & & & & & 67 & & 62 \\
\hline 60 & & & 66 & 63 & & & & 64 & \\
\hline 61 & 56 & 66 & & & 69 & 64 & & & \\
\hline 62 & & & & & & & 68 & & \\
\hline 63 & & & 67 & 64 & & & & 65 & 63 \\
\hline 64 & 57 & 67 & & & & 65 & 69 & & \\
\hline 65 & & & & & 70 & & & & \\
\hline
\end{tabular}




\section{Continued}

\begin{tabular}{|c|c|c|c|c|c|c|c|c|c|}
\hline 66 & 58 & 68 & 68 & 65 & & & & 66 & \\
\hline 67 & & & & & & 66 & 70 & & 64 \\
\hline 68 & & & & 66 & 71 & & & 67 & \\
\hline 69 & 59 & 69 & 69 & & & & 71 & & \\
\hline 70 & & & & 67 & 72 & 67 & & 68 & 65 \\
\hline 71 & 60 & & 70 & & & & 72 & & \\
\hline 72 & & 70 & & 68 & & 68 & & 69 & 66 \\
\hline 73 & 61 & & & & & 69 & 73 & & 67 \\
\hline 74 & & & 71 & 69 & 73 & & & 70 & \\
\hline 75 & 62 & 71 & & & & 70 & 74 & & 67 \\
\hline 76 & & & & 70 & & & & 71 & \\
\hline 77 & 63 & 72 & 72 & & 74 & & 75 & & 68 \\
\hline 78 & & & & 71 & & 71 & & 72 & \\
\hline 79 & 64 & 73 & & & & & 76 & & \\
\hline 80 & & & 73 & 72 & 75 & & & 73 & 69 \\
\hline 81 & 65 & 74 & & & & 73 & 77 & & 70 \\
\hline 82 & 66 & & 74 & 73 & 76 & & & 74 & \\
\hline 83 & & & & & & & 79 & 75 & 71 \\
\hline 84 & 67 & 75 & & 74 & 77 & 74 & 79 & & \\
\hline 85 & 68 & & 75 & & & & 80 & 76 & 72 \\
\hline 86 & 69 & & & 75 & 78 & 75 & 81 & 77 & \\
\hline 87 & 70 & 76 & 76 & 76 & 79 & 76 & 82 & 78 & 73 \\
\hline 88 & 71 & & & 77 & 80 & & 83 & & \\
\hline 89 & 72 & 77 & 77 & 78 & 81 & 77 & 84 & 79 & \\
\hline 90 & 73 & & 78 & 79 & & 78 & 85 & 80 & 74 \\
\hline 91 & 74 & 78 & 79 & 80 & 82 & 79 & 86 & 81 & \\
\hline 92 & 75 & & 80 & 81 & 83 & 80 & 87 & 82 & 75 \\
\hline 93 & 76 & 79 & 81 & 82 & 84 & 81 & 88 & 83 & \\
\hline 94 & $77-78$ & 80 & 82 & 83 & 85 & 82 & 89 & 84 & 76 \\
\hline 95 & $79-80$ & 81 & 83 & 84 & 86 & 83 & 90 & 85 & 77 \\
\hline 96 & 81 & $82-83$ & 84 & $85-86$ & 87 & 84 & 91 & 86 & 78 \\
\hline 97 & $82-83$ & 84 & 86 & $87-88$ & 88 & $85-86$ & $92-93$ & $87-88$ & $79-80$ \\
\hline 98 & $84-86$ & $85-87$ & $87-88$ & $89-91$ & $89-91$ & $87-89$ & $94-95$ & $91-98$ & $81-84$ \\
\hline 99 & $78-100$ & $88-100$ & $89-100$ & $92-100$ & $92-100$ & $91-100$ & $96-100$ & $92-100$ & $85-100$ \\
\hline
\end{tabular}


- Tow degree if the answer is (b).

- Three degrees if the answer is (c).

- Four degrees if the answer is (d).

- Zero degree if the answer is (f).

2) Sum the degrees of items of every intelligence, and recorded in the sample extract grading scale in column (a): the total column on the Table 7.

3) Divides the total score corresponding to each of intelligence on the number of the corresponding items in column (b) record the results in column (c).

4) The result in column (c) multiply with 20 and the output record in the last column which represents the participant raw degree of intelligence.

5) From the Table 6-table of criteria - the percentile extracts corresponding to the raw degree for each intelligences and those percentile recorded in the last column in the model.

6) Percentile represented on the profile sheet, as shown in the Figure 1.

7) The degree of any of the intelligences consider very high if the percentile are exceed 95.

8) The degree of any of the intelligences consider high if the percentile are between (85 and less than 95).

9) The degree of any of the intelligences consider above-average if the percentile are between (70 and less than 85). 70).

10) The degree of any of the intelligences consider at average if the percentiles are between ( 30 and less than

11) The degree of any of the intelligences consider less than average if the percentiles are between 15 and less than 30 .

12) The degree of any of the intelligences consider low if the percentiles are between (5 and less than 15).

13) The degree of any of the intelligences consider very low if the percentiles are less than 5.

Example: (case study).

Mohammad, male, 15 years: He has a medium degree of intelligence in most of the intelligences, except the personal intelligence and logical intelligence, where the degree of these two intelligences above average. As shown in the Figure 2.

\subsection{Raw Grades of Multiple Intelligences and Percentiles}

The following table shows the expected intelligences raw grades, the total of degrees and the corresponding percentiles.

\section{Discussion}

In the field of psychology and measurement, two psychometric properties of tests based on the theory validity and reliability were established typically to validate a theory of intelligence. Validity refers to the degree to which a test measures its intended attributes or desired outcomes, and there are many kinds of validity. In addition, reliability refers to the consistency of a tests result over time and is usually determined by using one or more of the following methods test-retest, equivalent-form, and split-half. Correlation is the statistical technique that almost all standardized intelligence test use to report the degree of validity and reliability. Reliability and validity are useful measures for testing the theoretical construct that human intelligence is a general ability that remains stable over time. Moreover, the validation of the original English version of Multiple Intelligence Development Assessment.

Scales (MIDAS) has been examined via a series of investigations, which evaluate its construct, concurrent, and predictive validity. Whereas there is a subset of MIDAS instrument that inquire the active participation and expressed enthusiasm for many of the MI activities. The MIDAS instrument was designed to provide an objective measure of the multiple intelligence as reported by the person or by a knowledgeable informant. However, The result of these study illustrate psychometric properties of the TEEN-MIDAS when self completed by adolescent from age 14 - 16, The instrument evidenced to high internal consistency by (Cronbach- $a$ ) formula ranged from 0.79 for spatial intelligence to 0.86 for intrapersonal intelligence, and 0.97 for the whole scale and moderate internal consistency by split-half procedure ranged from 0.73 for kinesthetic intelligence to 0.82 for the intrapersonal intelligence, and 0.88 for the whole scale, and strong test-retest reliability over a 2-week period ranged from 0.91 for naturalistic intelligence to 0.85 of intrapersonal intelligence, and 0.90 for the whole scale. 
Table 7. To extract the degrees of multiple intelligences, and their percentiles.

\begin{tabular}{|c|c|c|c|c|c|c|c|}
\hline Type intelligences & Sum (A) & (B) & & Sum $C=\frac{A}{B}$ & (D) & & Degree of intelligences $20 \times \mathrm{C}$ \\
\hline Musical & & $11 \backslash$ & $=$ & & $20 \times$ & $=$ & \\
\hline Kinesthetic & & $10 \backslash$ & $=$ & & $20 \times$ & $=$ & \\
\hline Logical & & $9 \backslash$ & $=$ & & $20 \times$ & $=$ & \\
\hline spatial & & $10 \backslash$ & $=$ & & $20 \times$ & $=$ & \\
\hline Linguistic & & $13 \backslash$ & $=$ & & $20 \times$ & $=$ & \\
\hline Interpersonal & & 141 & $=$ & & $20 \times$ & $=$ & \\
\hline Intrapersonal & & $13 \backslash$ & $=$ & & $20 \times$ & $=$ & \\
\hline Natural & & $13 \backslash$ & $=$ & & $20 \times$ & $=$ & \\
\hline Total multiple intelligences & & 931 & $=$ & & & $=$ & \\
\hline
\end{tabular}

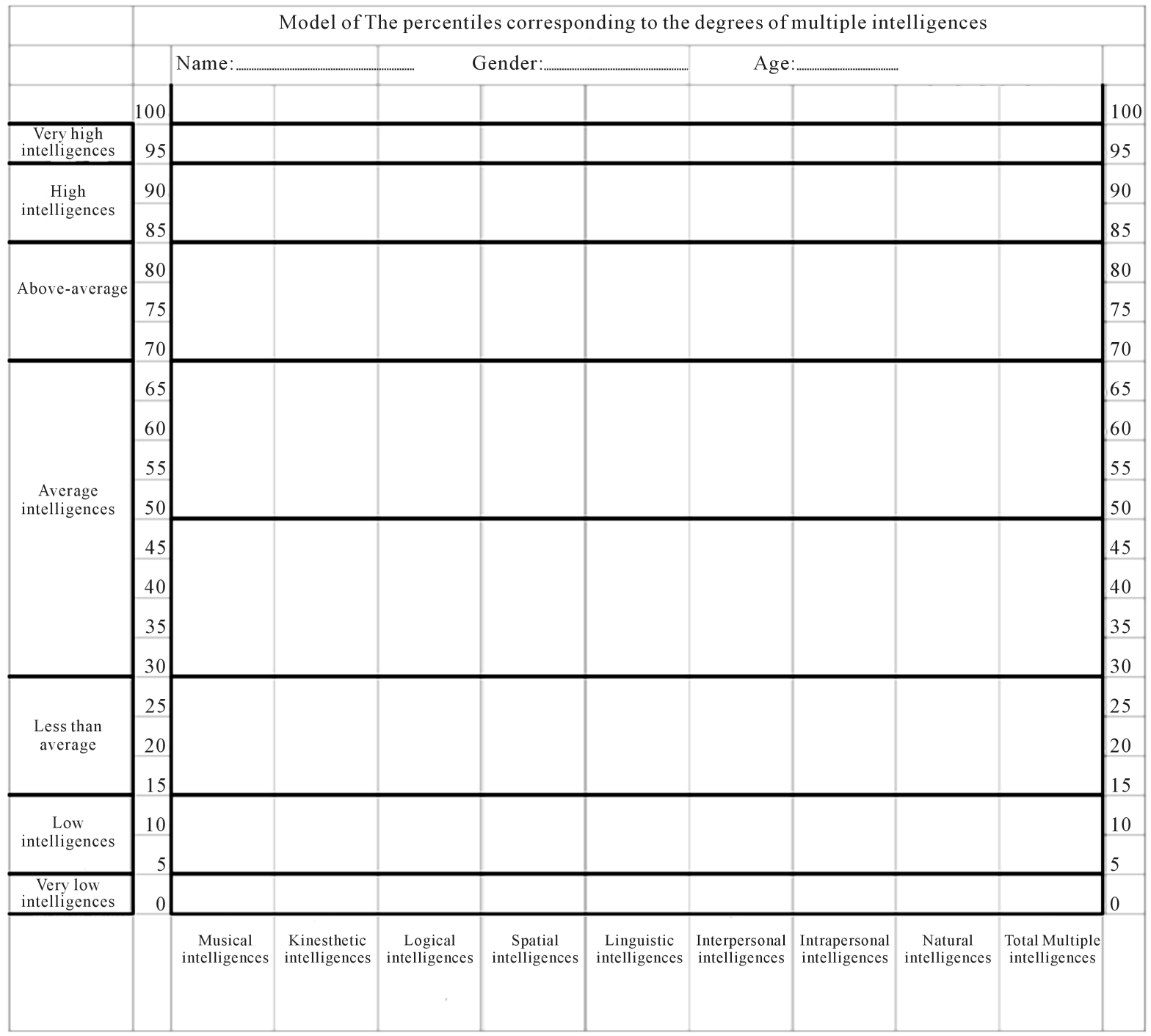

Figure 1. The profile sheet of the multiple intelligences percentile. 


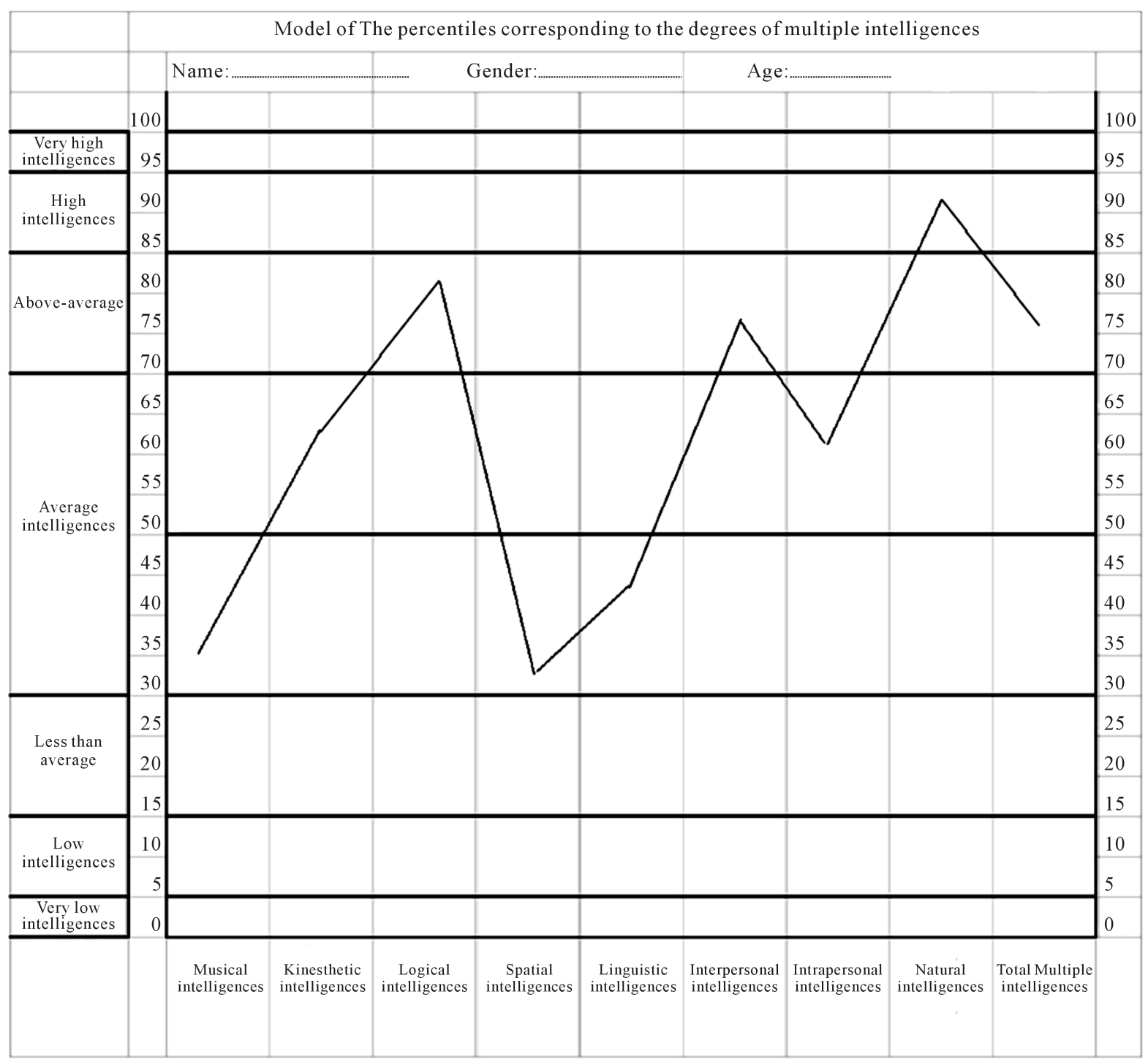

Figure 2. The profile sheet of the case multiple intelligences percentile.

Also, and after translation of the test constructive validity of the scale was examined by expert judgment and pilot study, the finding indicated that the content of the Arabic version of TEEN-MIDAS need to modified to match the Arabic content, and the result revealed that 26 items were removed from Arabic version, the remaining 93 items formed the final Arabic version of TEEN-MIDAS. Factorial validity shows that all the subscale result are greater than 0.39 which improve the scale construction, Discriminatory validity was done by examine the differences of intelligence degree among gifted and non-gifted students, the result show that the gifted students have high degree than non-gifted students on all of intelligence which improve the theoretical background, Also Discriminatory validity examined by the differences of intelligence degree according to the gender, the female tended to do better in musical intelligence, spatial intelligence, and linguistic intelligence, while the male have a high performance in naturalistic intelligence. However, from the investigation of the MIDAS validity in this study, the validated Arabic version is effective in measuring students' MI in their schools. The examination and adaptation of the items revealed that, the items are matching with the Arabic culture, which enable the Arabic educators to use an Arabic version of MIDAS in measuring students' MI in any Arabic region. There are several implementations of the MIDAS instrument for the educators, companies, and students. The Arabic version of MIDAS in this study provides a lot of information about the students' MI in their early education and in their secondary schools. This instrument can be helpful for students to understand themselves and their specific 
strength and weaknesses, In addition, one of the implications of the Arabic version of MIDAS for students is the vocational counseling, which enables them to determine whether to continue their studies in the academic stream or in the vocational stream based on their intelligence inclinations and interests, which can be measured by using MIDAS scale.

In the education field, the MI theory should be included into the educational system in Jordan in order to involve students with various activities that may be able to improve their multiple intelligence skills.

The Arabic version of MIDAS in this study provides teachers with additional information in their students' thinking and behaviorism.

\section{Recommendation of the Study}

Based on the results of this study, the following recommendations and suggestions were formulated:

1) The use of adapted and validated Arabic version of MIDAS instrument into the consulting processes in Jordan's schools will enable the counselors and the teachers to better understand their students' intelligences. They can use MIDAS instrument to promote the use of strength-based learning activities to enhance instructional practice and personal improvement.

2) The use of adapted MIDAS to measure students intelligence can be used by teachers and parents to assist the students in vocational counseling to determine whether to continue their studies in the academic schools or in the vocational schools based on their intelligence strengths and interests.

3) The contents of Arabic version of MIDAS need to be included into the schools' curricula, such as the music, spatial, kinesthetic, intrapersonal, interpersonal intelligence, to giving attention to cultivate the students' various talents.

\section{References}

Armstrong, T. (1994). Multiple Intelligence in the Classroom. Alexandria, VA: Association for Supervision and Curriculum Development.

Armstrong, T. (1999). Seven Kinds of Smart: Identifying and Developing Your Multiple Intelligence. New York: Plume.

Byrd, M., \& Stacey, B. (1993). Bias in IQ Perception. The Psychologist, 5, 309-311.

Chen, J. (2004). Theory of Multiple Intelligence: Is It a Scientific Theory? Teacher College Record, 106, 17-23.

Collins, J. (1998). Seven Kinds of Smart. Time, 152, 94-96.

Deary, I. (2000). Looking down on Human Intelligence. Oxford: Oxford University Press.

Deary, I. (2001). Intelligence: A Very Short Introduction. Oxford: Oxford University Press.

Eisner, E. W. (1994). Putting Multiple Intelligences in Context: Some Questions and Observations. Teachers College Record, 15, 555-560.

Esters, G., \& Ittenbach, F. (1999). Contemporary Theories and Assessments of Intelligence: A Primer. Career and Technical Education. University of Southwestern Journal, 2, 373-376.

Eysenck, J. (1998). Intelligence: A New Look. London: Transaction Publishers.

Gardner, H. (1983). Frames of Mind: The Theory of Multiple Intelligences, Library of Congress Cataloging (pp. 3-12). New York: Basic Books.

Gardner, H. (1993). Frames of Mind: The Theory of Multiple Intelligences, Library of Congress Cataloging (pp. 73-237). New York: Basic Books.

Gardner, H. (1994). Intelligence in Theory and Practice: A Response to Elliot W. Eisner, Robert J. Sternberg, and Henry M. Levin. Teachers College Record, 95, 576-583.

Gardner, H. (1999). Intelligences Reframed, Library of Congress Cataloging (pp. 27-47). New York: Basic Books.

Gould, S. J. (1981). The Mismeasure of Man. New York: WW Norton.

Horn, J. L. (1989). Cognitive Diversity: A Framework for Learning. In P. L. Ackerman, R. J. Sternberg, \& R. Glaser (Eds.), Learning and Individual Differences: Advances in Theory and Research (pp. 61-116). New York: W.H. Freeman.

Mackintosh, N. (1998). IQ and Human Intelligence. Oxford: Oxford University Press.

Murphy, G. (1949). Historical Introduction to Modern Psychology. New York: Harcot, Brace \& CO.

Parmalee, R., \& Oakland, T. (1985). Mental Measurement of Minority-Group Children. In B. B. Wolman (Ed.), Handbook of Intelligence: Theories, Measurement, and Applications (pp. 59-118). New York: Wiley. 
Paulhus, D. (2000). Nomination of Intelligence Exemplars. Social Cognition, 18, 319-328. http://dx.doi.org/10.1521/soco.2000.18.4.319

Shearer, B. (1991). An Investigation into the Validity, Reliability and Clinical Utility of the Hillside Assessment of Perceived Intelligences. (Doctoral Dissertation, Union Institute, 1991). Dissertation Abstracts International, 52, 6647B.

Shearer, B. (1996b). The MIDAS: A Professional Manual. Multiple Intelligences Research and Consulting. Kent, Ohio, 106, 17-23. http://www.tcrecord.org

Shearer, C. B. (1996a). The MIDAS: A Guide to Assessment and Education for the Multiple Intelligences. [Brochure]. Columbus, OH: Greyden.

Shearer, C. B. (1997). Reliability, Validity, and Utility of a Multiple Intelligences Assessment for Career Planning. Paper Presented at the 105th Annual Convention of the American Psychological Association, Chicago.

Shearer, C. B., \& Jones, J. A. (1994). The Validation of the Hillside Assessment of Perceived Intelligence (HAPI): A Measure of Howard Gardner's Theory of Multiple Intelligence. Poster Presented at the Annual Meeting of the American Education Research Association, New Orleans.

Spearman, C. (1927). The Abilities of Man. New York: MacMillan.

Sternberg, R. J. (1990). Metaphors of Mind: Conception of the Nature of Intelligence. Cambridge: Cambridge University Press.

Sternberg, R. J. (1994). Reforming School Reform: Comments on Multiple Intelligences: The Theory in Practice. Teachers College Record, 95, 561-569.

Sternberg, R. J., \& Kaufman, J. C. (1998). Human Abilities. Annual Review of Psychology, 49, 479-502. http://dx.doi.org/10.1146/annurev.psych.49.1.479

Thurston, L. L. (1938). Primary Mental Abilities. Chicago: University of Chicago Press.

Traub, J. (1998). Multiple Intelligence Disorder. The New Republic, 219, 20-23.

Vernon, P. E. (1979). Intelligence: Heredity and Environmental. San Francisco: Freeman and Company.

Way, D., \& Shearer, B. (1990). Phase I: Development of the Hillside Assessment of Pre-Trauma Intelligences. Paper Presented at the Midwest Educational Research Association, Chicago.

Wiswell, A., Hardy, C. R., \& Reio, T. G. (2001). An Examination of Multiple Intelligence Developmental Assessment Scales (MIDAS). Paper Presented at the Annual Meeting of the Academy of Human Resource Development, Tulsa.

Yoong, S. (2000). Multiple Intelligence: A Construct Validation of the MIDAS Scale in Malaysia. Paper Presented at the International Conference on Measurement and Evaluation in Education, Penang. 